\title{
NGHIÊN CÚU NHÂN GIỐNG IN VITRO VÀ SỬ SINH TRƯỞNG PHÁT TRIỂN CÂY GIẢO CỔ LAM ( GYNOSTEMMA PUBESCENS) TRONG NHÀ KÍNH
}

\section{Nguyễn Thị Thanh Hằnga, Lê Ái Vâna, Đinh Văn Khiêma , Hoàng Văn Cương ${ }^{a}$, Nguyễn Thị Phượng Hoànga ${ }^{a}$ Phan Xuân Huyêna ${ }^{\text {* }}$}

${ }^{a}$ Viện Nghiên cưu Khoa học Tây Nguyên, Viện Hàn lâm Khoa học và Công nghệ Việt Nam, Lâm Đồng, Việt Nam

*Tác giả liên hệ: Email: phanxuanhuyen1974@gmail.com

Lịch sử bài báo

Nhận ngày 01 tháng 09 năm 2018

Chỉnh sửa ngày 17 tháng 09 năm 2018 | Chấp nhận đăng ngày 20 tháng 09 năm 2018

\section{Tóm tắt}

Cây Giảo cổ lam (Gynostemma pubescens) phân bố chủ yếu tại các tỉnh phía Bắc, là một trong nhũng loại thảo dược quí và tốt cho sức khỏe của con người. Trong nghiên cúu này, chúng tôi nghiên cứu nhần giống in vitro và nuôi trồng đánh giá sự sinh truởng phát triển cây Giảo cổ lam cấy mô trong nhà kính tại Đà Lạt, Lâm Đồng. Kết quả cho thấy, môi trưòng MS (Murashige Skoog) bổ sung $1 \mathrm{mg} / \mathrm{l}$ BA, 30g/l sucrose, $8 \mathrm{~g} / \mathrm{l}$ agar, pH 5.8 là tốt nhất đến sự tái sinh chồi in vitro, với chiều cao chồi $1.84 \mathrm{~cm}$, số chồi 10.50 chồi/mẫu. Môi truoòng $\mathrm{MS}$ bổ sung $0.5 \mathrm{mg} / \mathrm{l} \mathrm{TDZ}, 30 \mathrm{~g} / \mathrm{l}$ sucrose, $8 \mathrm{~g} / \mathrm{l}$ agar, $\mathrm{pH} 5.8$ là tốt nhất đến sư tái sinh chồi in vitro, với chiều cao chồi $1.99 \mathrm{~cm}$, số chồi 13.80 chồi/mẫu. Nồng độ IBA tù $0-1$ $\mathrm{mg} / \mathrm{l}$ đều thích hợp đến sư tái sinh rễ in vitro của cây Giảo cổ lam, với tỉ lệ tái sinh rễ đạt $100 \%$. Vụn xo dìa là giá thể thích hợp nhất để chuyến cây Giảo cổ lam cấy mô ra ngoài vuờn voom, với tỷ lệ sống đạt $100 \%$, chiều cao cây $9.73 \mathrm{~cm}$, chiều dài rễ $6.45 \mathrm{~cm}$. Đất mùn là giá thể tốt nhất đển sư sinh truơng phát triển của cây, với tỷ lệ sống đạt $100 \%$, chiều cao cây $82.08 \mathrm{~cm}$, chiều dài rê̂ $36.57 \mathrm{~cm}$, khối luợng tuooi $57.32 \mathrm{~g} / \mathrm{cây}$. Tưới $100 \mathrm{ml}$ phân Nitrophoska $(2 \mathrm{~g} / \mathrm{l})$ theo định kỳ mỗi tuần một lần là tốt nhất đển sụ sinh truởng phát triển của cây, với tỷ lệ sống đạt $100 \%$, chiều cao cây $94.22 \mathrm{~cm}$, chiều dài rễ $37.71 \mathrm{~cm}$, khối luợng tuooi $59.38 \mathrm{~g} / \mathrm{cây}$.

Từ khóa: Chiều cao cây; Chiều dài rễ; Cây Giảo cổ lam; Sinh trưởng phát triển; Số chồi.

Mã số định danh bài báo: http://tckh.dlu.edu.vn/index.php/tckhdhdl/article/view/506

Loại bài báo: Bài báo nghiên cứu gốc có bình duyệt

Bản quyền @ 2018 (Các) Tác giả.

Cấp phép: Bài báo này được cấp phép theo CC BY-NC-ND 4.0 


\title{
STUDY ON IN VITRO PROPAGATION AND DEVELOPMENT GROWTH OF GYNOSTEMMA PUBESCENS IN THE GREENHOUSE CONDITION
}

\section{Nguyen Thi Thanh Hanga, Le Ai Van ${ }^{a}$, Dinh Van Khiem ${ }^{a}$, Hoang Van Cuong ${ }^{\mathrm{a}}$, Nguyen Thi Phuong Hoang ${ }^{\mathrm{a}}$, Phan Xuan Huyen ${ }^{{ }^{*}}$}

${ }^{a}$ The Tay Nguyen Institute for Scientific Research, Vietnam Academy of Science and Technology, Lamdong, Vietnam

*Corresponding author: Email: phanxuanhuyen1974@gmail.com

\section{Article history}

Received: September 01 ${ }^{\text {st }}, 2018$

Received in revised form: September 17 th $^{\text {th }} 2018 \mid$ Accepted: September $20^{\text {th }}, 2018$

\begin{abstract}
The Gynostemma pubescens plant, which is distributed mainly over the northern provinces, is a valuable and beneficial herb for human health. In this study, we investigated in vitro propagation and cultivation to evaluate the growth and development of Gynostemma pubescens in greenhouse conditions at Dalat city, Lamdong province. The results showed that MS medium supplemented with $1 \mathrm{mg} / \mathrm{l} \mathrm{BA,} 30 \mathrm{~g} / \mathrm{l}$ sucrose, $8 \mathrm{~g} / \mathrm{l}$ agar, $\mathrm{pH} 5.8$ was the best medium for shoot regeneration in vitro, with a shoot height of $1.84 \mathrm{~cm}$, and 10.50 shoots/explant. The MS medium contained $0.5 \mathrm{mg} / \mathrm{l} \mathrm{TDZ,} \mathrm{30g/l} \mathrm{sucrose,} 8 \mathrm{~g} / \mathrm{l}$ agar, $\mathrm{pH} 5.8$ was the most suitable medium for shoot regeneration in vitro, with a shoot height of $1.99 \mathrm{~cm}$, and 13.80 shoots/explant. Concentrations of IBA from 0 to $1 \mathrm{mg} / \mathrm{l}$ were appropriate for in vitro root regeneration, yielding a root regeneration rate of $100 \%$. Coconut fiber powder was the most suitable substrate to transfer the plantlets to the greenhouse, with a survival rate of $100 \%$, plant height of $9.73 \mathrm{~cm}$, and root length of $6.45 \mathrm{~cm}$. Humus proved the best substrate for plant development and growth, with a survival rate of $100 \%$, plant height of $82.08 \mathrm{~cm}$, root length of $36.57 \mathrm{~cm}$ and a fresh weight of $57.32 \mathrm{~g} /$ plant. Watering with $100 \mathrm{ml}$ of Nitrophoska fertilizer $(2 \mathrm{~g} / \mathrm{l})$ once a week was the best for plant growth, with a survival rate of $100 \%$, height of $94.22 \mathrm{~cm}$, root length of $37.71 \mathrm{~cm}$, and a fresh weight of $59.38 \mathrm{~g} / \mathrm{plant}$.
\end{abstract}

Keywords: Development growth; Gynostemma pubescens; Number of shoots; Plant height; Root length.

Article identifier: http://tckh.dlu.edu.vn/index.php/tckhdhdl/article/view/506

Article type: (peer-reviewed) Full-length research article

Copyright (C) 2018 The author(s).

Licensing: This article is licensed under a CC BY-NC-ND 4.0 


\section{GIỚI THIỆU}

Giảo cổ lam (Gynostemma pubescens) là một cây thuốc quý và có giá trị kinh tế cao, có chứa hơn 100 loại saponin, trong đó có nhiều cấu trúc giống như saponin của nhân sâm và tam thất. Cây Giảo cổ lam có công dụng bồi bổ và tăng cường sức khỏe, chống lão hóa, tăng cường giải độc chức năng gan, hỗ trợ điều trị bệnh ung thư, giảm béo phì, điều chỉnh rối loạn chuyển hóa mỡ máu, đường huyết, huyết áp, tim mạch,... (Đỗ, 1999; Võ, 1997). Do đó, việc tiến hành nghiên cứu bảo tồn và phát triển cây Giảo cổ lam nhằm tạo ra nguồn nguyên liệu dược phục vụ trong lĩnh vực y học, thực phẩm và mỹ phẩm là vấn đề rất cần thiết. Trên thế giới hiện nay đã có nhiều công bố nghiên cứu trên cây Giảo cổ lam, nghiên cứu chống ung thư (Cheng \& ctg., 2011; Li, Lin, Huang, Xie, \& Ma, 2016), nghiên cứu xác định những saponin và tác dụng của chúng (Huo, Wang \& Xiao, 1998; Utama-ang \& ctg., 2006), nghiên cứu thành phần hóa học trong cây Giảo cổ lam (Xie \& ctg., 2010; Yin \& Hu, 2016), về nghiên cứu nhân giống in vitro đã có công bố nhưng vẫn còn rất ít (Zhang, Liu, Zhao, \& Han, 1988; Jala \& Patchpoonporn, 2012). Ở nước ta, cây Giảo cổ lam đã được trồng ở một số tỉnh phía Bắc và đã tạo ra nguyên liệu dược liệu phục vụ cho việc chữa bệnh, nhưng về công bố nghiên cứu trên cây Giảo cổ lam vẫn còn rất ít, Bùi và ctg. (2015) đã nghiên cứu nhân giống in vitro thành công loài Gynostemma pentaphyllum, Pham và Tran (2017) nghiên cứu bảo tồn và phát triển cây Giảo cổ lam. Vì vậy, chúng tôi tiến hành nghiên cứu nhân giống in vitro và đánh giá sự sinh trưởng phát triển cây Giảo cổ lam cấy mô trong điều kiện nhà kính tại Đà Lạt - Lâm Đồng. Kết quả của nghiên cứu này góp phần xây dựng qui trình nhân giống in vitro và qui trình nuôi trồng cây Giảo cổ lam tại Đà Lạt, Lâm Đồng.

\section{VẬT LIỆU VÀ PHƯƠNG PHÁP NGHIÊN CÚU}

\subsection{Vật liệu}

Loài Gynostemma pubescens đã và đang được nghiên cứu tại Phòng Công nghệ Thực vật, Viện Nghiên cứu Khoa học Tây Nguyên được sử dụng làm nguồn vật liệu cho các thí nghiệm.

\subsection{Phương pháp nghiên cứu}

\subsubsection{Môi truò̀ng và điều kiện nuôi cấy}

MS (Murashige \& Skoog, 1962) là môi trường được sử dụng trong nghiên cứu in vitro, tùy theo mục đích của các thí nghiệm mà bổ sung các chất như: BA (6-benzyl adenin), TDZ (Thidiazuron), IBA (Indole-3-butyric), sucrose và agar. Đối với những nghiên cứu in vitro, thời gian chiếu sáng 10 giờ/ngày, cường độ ánh sáng $34 \mu \mathrm{mol} \cdot \mathrm{m}^{-2} \cdot \mathrm{s}^{-}$ ${ }^{1}$, nhiệt độ $25 \pm 2^{\circ} \mathrm{C}$ và độ ẩm không khí 75-85\%. Đối với những nghiên cứu ex vitro, các thí nghiệm được tiến hành trong điều kiện nhà kính. Giá thể sử dụng là cát, vụn xơ 
dừa, đất mùn, đất bazan. Phân bón tưới cho cây là phân hữu cơ sinh học bón lá Vinh Thanh Humic Acid (2 g/l), Nutri-Gold (2 g/l), Nitrophoska (2 g/l) và Growmore (2 g/l).

\subsubsection{Bố trí thí nghiệm}

- Thí nghiệm 1: Khảo sát ảnh hưởng của BA đến sự tái sinh chồi in vitro: Vật liệu nuôi cấy là những đốt thân in vitro (Hình 1a) được cấy trên môi trường MS bổ sung $0 ; 0.5 ; 1 ; 1.5 ; 2 \mathrm{mg} / 1 \mathrm{BA}, 30 \mathrm{~g} / \mathrm{l}$ sucrose, $8 \mathrm{~g} / \mathrm{l}$ agar, $\mathrm{pH}$ 5.8. Mỗi nghiệm thức cấy 12 mẫu, sau 30 ngày nuôi cấy tiến hành thu số liệu. Chỉ tiêu theo dõi là số chồi/mẫu và chiều cao chồi $(\mathrm{cm})$.

- Thí nghiệm 2: Khảo sát ảnh hưởng của TDZ đến sự tái sinh chồi in vitro: Vật liệu nuôi cấy là những đốt thân in vitro (Hình $1 \mathrm{a}$ ) được cấy trên môi trường MS bổ sung $0 ; 0.1 ; 0.5 ; 1 \mathrm{mg} / 1 \mathrm{TDZ}, 30 \mathrm{~g} / \mathrm{l}$ sucrose, $8 \mathrm{~g} / \mathrm{l}$ agar, $\mathrm{pH}$ 5.8. Mỗi nghiệm thức cấy 12 mẫu, sau 30 ngày nuôi cấy tiến hành thu số liệu. Chỉ tiêu theo dõi là số chồi/mẫu và chiều cao chồi $(\mathrm{cm})$.

- Thí nghiệm 3: Khảo sát ảnh hưởng của IBA đến sự tái sinh rễ in vitro: Vật liệu nuôi cấy là những chồi ngọn in vitro (Hình 1a) được cấy trên môi trường MS bổ sung $0 ; 0.1 ; 0.5 ; 1 \mathrm{mg} / \mathrm{l} \mathrm{IBA}, 30 \mathrm{~g} / \mathrm{l}$ sucrose, $8 \mathrm{~g} / \mathrm{l}$ agar, $\mathrm{pH} 5.8$. Mỗi nghiệm thức cấy 12 mẫu, sau 20 ngày nuôi cấy tiến hành thu số liệu. Chỉ tiêuu theo dõi là chiều cao cây $(\mathrm{cm})$, chiều dài rễ $(\mathrm{cm})$, số rễ/cây và tỉ lệ tạo rễ $(\%)$.

- Thí nghiệm 4: Khảo sát ảnh hưởng của giá thể đến tỉ lệ sống của cây Giảo cổ lam cấy mô chuyển ra ngoài vườn ươm: Những cây Giảo cổ lam cấy mô có đầy đủ thân lá rễ và chiều cao khoảng $5 \mathrm{~cm}$ (Hình $2 \mathrm{a}$ ) được trồng trên giá thể cát, vụn xơ dừa và giá thể $1 / 2$ vụn xơ dừa phối trộn $1 / 2$ cát. Mỗi nghiệm thức trồng 12 cây, sau 45 ngày nuôi trồng tiến hành thu số liệu. Chỉ tiêu theo dõi là chiều cao cây $(\mathrm{cm})$, chiều dài rễ $(\mathrm{cm})$ và tỉ lệ sống của cây $(\%)$.

- Thí nghiệm 5: Khảo sát ảnh hưởng của giá thể đến sự sinh trưởng phát triển của cây Giảo cổ lam cấy mô trong nhà kính: Những cây Giảo cổ lam cấy mô có đầy đủ thân lá rễ và chiều cao khoảng $8 \mathrm{~cm}$ (Hình $2 \mathrm{~b}$ ) được trồng trên giá thể đất mùn, vụn xơ dừa và đất bazan, với mật độ 1 cây/chậu. Mỗi nghiệm thức trồng 12 cây, sau 90 ngày nuôi trồng tiến hành thu số liệu. Chỉ tiêu theo dõi là chiều cao cây $(\mathrm{cm})$, chiều dài rễ $(\mathrm{cm})$, khối lượng tươi/cây $(\mathrm{g})$ và tỉ lệ sống của cây $(\%)$.

- Thí nghiệm 6: Khảo sát ảnh hưởng của phân bón đến sự sinh trưởng phát triển cây Giảo cổ lam cấy mô trong nhà kính: Những cây Giảo cổ lam cấy mô có đầy đủ thân lá rễ và chiều cao khoảng $8 \mathrm{~cm}$ (Hình $2 \mathrm{~b}$ ) được trồng trên cùng giá thể vụn xơ dừa, với mật độ 1 cây/chậu. Các nghiệm thức được tưới $100 \mathrm{ml}$ phân hữu cơ sinh học bón lá Vinh Thanh Humic Acid, Nutri- 
Gold, Nitrophoska và Growmore vào chậu giá thể theo định kỳ 1 tuần 1 lần. Mỗi nghiệm thức trồng 12 cây, sau 90 ngày nuôi trồng tiến hành thu số liệu. Chỉ tiêu theo dõi là chiều cao cây $(\mathrm{cm})$, chiều dài rễ $(\mathrm{cm})$, khối lượng tươi/cây $(\mathrm{g})$ và tỉ lệ sống của cây $(\%)$.

\subsection{Xử lý số liệu}

Số liệu của các thí nghiệm được xử lý bằng phần mềm thống kê SPSS (bản 15.0) trong Duncan's test (Duncan, 1955) với $P \leq 0.05$.

\section{KẾT QUẢ VÀ THẢO LUẬN}

\subsection{Khảo sát ảnh hưởng của $\mathrm{BA}$ đến sự tái sinh chồi in vitro}

Khả năng tái sinh chồi in vitro sau 30 ngày nuôi cấy được thể hiện trên Bảng 1 . Kết quả cho thấy, tất cả các mẫu ở những môi trường trên đều sống sót và tái sinh chồi, tuy nhiên ở những môi trường khác nhau thì quá trình tái sinh chồi có sự khác nhau. Môi trường bổ sung $1 \mathrm{mg} / \mathrm{l}$ BA tái sinh chồi cao nhất, với 10.5 chồi/mẫu, chồi cây khỏe mạnh và có màu xanh đậm (Hình $1 \mathrm{~b}$ ). Nồng độ của $\mathrm{BA}$ tăng từ 0 đến $0.5 \mathrm{mg} / \mathrm{l}$ thì sự tái sinh chồi tăng lên (tương ứng 3.10 và 6.80 chồi/mẫu, chồi cây khỏe mạnh và có màu xanh đậm (Hình $1 \mathrm{~b}$ ), nhưng khi nồng độ $\mathrm{BA}$ tăng lên 1.5 đến $2 \mathrm{mg} / \mathrm{l}$ thì sự tái sinh chồi giảm xuống (tương ứng 6.90 và 5.70 chồi/mẫu), chồi cây yếu và có hiện tượng mọng nước (Hình $1 \mathrm{~b}$ ). Điều này cho thấy, nồng độ $\mathrm{BA}$ từ 0 đến $1 \mathrm{mg} / \mathrm{l}$ thì có tác dụng kích thích tái sinh chồi, nhưng khi nồng độ BA tăng lên 1.5 đến $2 \mathrm{mg} / \mathrm{l}$ thì có tác dụng ức chế sự hình thành chồi.

Bảng 1. Ảnh hưởng của BA đến sự tái sinh chồi in vitro sau 30 ngày nuôi cấy

\begin{tabular}{lll}
\hline BA $(\mathrm{mg} / \mathrm{l})$ & Số chồi/mẫu & Chiều cao chồi $(\mathrm{cm})$ \\
\hline 0.0 & $3.10^{\mathrm{d}^{*}}$ & $2.82^{\mathrm{a}}$ \\
0.5 & $6.80^{\mathrm{b}}$ & $2.18^{\mathrm{b}}$ \\
1.0 & $10.50^{\mathrm{a}}$ & $1.84^{\mathrm{bc}}$ \\
1.5 & $6.90^{\mathrm{b}}$ & $1.42^{\mathrm{cd}}$ \\
2.0 & $5.70^{\mathrm{c}}$ & $1.29^{\mathrm{d}}$ \\
\hline
\end{tabular}

Ghi chú: *Những chữ khác nhau $(\mathrm{a}, \mathrm{b}, \mathrm{c}, \mathrm{d})$ trong cùng một cột biểu diễn sự khác nhau có ý nghĩa với $P \leq 0.05$ trong Duncan's test; $\mathrm{n}=12$.

Kết quả của thí nghiệm này cũng cho thấy, khi nồng độ BA tăng lên thì chiều cao chồi giảm xuống, khi tăng nồng độ $\mathrm{BA}$ thì sẽ ức chế sự tăng trưởng chiều cao của chồi cây. BA là chất điều hòa sinh trưởng thuộc nhóm cytokinin có vai trò quan trọng trong phân chia tế bào và kích thích sự hình thành chồi, bởi vậy, trong nuôi cấy mồ tế bào thực vật $\mathrm{BA}$ thường được sử dụng trong giai đoạn nhân nhánh. Nồng độ của $\mathrm{BA}$ được sử dụng trong nhân giống in vitro ở những loài cây khác nhau là khác nhau, có 
loài cây thích hợp ở nồng độ thấp, có loài cây thích hợp ở nồng độ cao. Hiện nay, đã có một số công bố đã sử dụng $\mathrm{BA}$ trong nghiên cứu nhân giống in vitro cây Giảo cổ lam, nhưng vẫn còn rất ít.

Kết quả của thí nghiệm này tương đồng với kết quả nghiên cứu của Jala và Patchpoonporn (2012) khi nghiên cứu nhân giống in vitro cây Giảo cổ lam đã sử dụng $\mathrm{BA}$, kết quả cho thấy, BA ở nồng độ $1 \mathrm{mg} / 1$ là tốt nhất, với 7.285 chồi $/ \mathrm{mẫu}$. Pham và Tran (2017) nghiên cứu bảo tồn và phát triển cây Giảo cổ lam đã sử dụng BA kết hợp với NAA, kết quả thu được tốt nhất khi BA ở nồng độ $1 \mathrm{mg} / \mathrm{l}$ và NAA ở nồng độ $0.1 \mathrm{mg} / \mathrm{l}$, với 6.8 chồi/mẫu. Bùi và ctg. (2015) nghiên cứu nuôi cấy mô cây Giảo cổ lam đã sử dụng $0.5 \mathrm{mg} / \mathrm{l}$ BA kết hợp $0.4 \mathrm{mg} / \mathrm{l}$ Kinetin cho hệ số nhân nhanh chồi đạt 4.36 lần. Như vậy, môi trường MS bổ sung $1 \mathrm{mg} / \mathrm{l} \mathrm{BA}$ là thích hợp nhất đến sự nhân nhanh in vitro cây Giảo cổ lam.

\subsection{Khảo sát ảnh hưởng của $\mathrm{TDZ}$ đến sự tái sinh chồi in vitro}

Khả năng tái sinh chồi in vitro sau 30 ngày nuôi cấy được thể hiện trên Bảng 2. Kết quả cho thấy, môi trường không bổ sung chất kích thích sinh trưởng thì mẫu chỉ tái sinh 3.20 chồi/mẫu và chồi cây khỏe mạnh (Hình $1 \mathrm{c}$ ), khi môi trường bổ sung $0.1 \mathrm{mg} / \mathrm{l}$ TDZ thì mẫu tái sinh chồi tăng lên 7.80 chồi/mẫu và chồi cây xanh mượt (Hình 1c), khi tăng nồng độ TDZ lên $0.5 \mathrm{mg} / \mathrm{l}$ thì mẫu tái sinh chồi nhiều nhất, với 13.80 chồi/mẫu và chồi cây xanh mượt (Hình 1c), nhưng khi tăng cao nồng độ TDZ lên $1 \mathrm{mg} / 1$ thì mẫu chỉ tái sinh 6.60 chồi/mẫu, chồi cây yếu và có hiện tượng mọng nước (Hình $1 \mathrm{c}$ ). Điều này cho thấy, TDZ ở nồng độ thấp thì kích thích tái sinh chồi của mẫu, nhưng khi nồng độ TDZ tăng cao thì ức chế sự tái sinh chồi của mẫu. Kết quả cũng cho thấy, nồng độ TDZ càng tăng cao $(0,0.1,0.5,1 \mathrm{mg} / \mathrm{l})$ thì chiều cao chồi càng giảm xuống (tương ướng 2.79 , $1.31,1.99,0.83 \mathrm{~cm})$. TDZ là chất kích thích sinh trưởng có tác dụng kích thích sự phân chia tế bào và hình thành chồi trong nhân giống thực vật in vitro.

\section{Bảng 2. Ảnh hưởng của TDZ đến sự tái sinh chồi in vitro sau 30 ngày nuôi cấy}

\begin{tabular}{lll}
\hline TDZ $(\mathrm{mg} / \mathrm{l})$ & Số chồi/mẫu & Chiều cao chồi $(\mathrm{cm})$ \\
\hline 0.0 & $3.20^{\mathrm{d}^{*}}$ & $2.79^{\mathrm{a}}$ \\
0.1 & $7.80^{\mathrm{b}}$ & $1.31^{\mathrm{c}}$ \\
0.5 & $13.80^{\mathrm{a}}$ & $1.99^{\mathrm{b}}$ \\
1.0 & $6.60^{\mathrm{c}}$ & $0.83^{\mathrm{c}}$ \\
\hline
\end{tabular}

Ghi chú: *Những chữ khác nhau $(\mathrm{a}, \mathrm{b}, \mathrm{c}, \mathrm{d})$ trong cùng một cột biểu diễn sự khác nhau có ý nghĩa với $P \leq 0.05$ trong Duncan's test; $\mathrm{n}=12$.

Hiện nay, TDZ được ứng dụng rộng rãi trong nuôi cấy mô tế bào thực vật trên nhiều đối tượng cây trồng, nhưng chưa thấy nghiên cứu nào công bố sử dụng TDZ trong nhân giống in vitro cây Giảo cổ lam. Đoàn (2014) nghiên cứu nhân giống cây dược liệu đảng sâm và cho thấy môi trường $1 / 2 \mathrm{MS}$ bồ sung $0.1 \mathrm{mg} / \mathrm{TDZ}$ kết hợp $2 \mathrm{mg} / 12.4 \mathrm{D}$ là thích hợp nhân nhanh callus. Slupski, Tubek, và Matkowski (2011) nghiên cứu nhân 
giống cây dược liệu đảng sâm và cũng cho thấy khi bổ sung TDZ vào môi trường thì thúc đẩy quá trình tạo cụm chồi. Phan, Hoàng, Đinh, Nguyễn, và Nguyễn (2015) nghiên cứu nhân giống cây hoa lan Miltonia sp. khi bổ sung $\mathrm{TDZ}$ vào môi trường nuôi cấy thì thúc đẩy sự hình thành protocorms, nồng độ thích hợp nhất của TDZ đã tạo được 26.20 protocorms/mẫu, trong khi đó nồng độ thích hợp nhất của BA chỉ tạo được 22.20 protocorms/mẫu. Như vậy, môi trường MS bổ sung $0.5 \mathrm{mg} / \mathrm{l} \mathrm{TDZ}$ là thích hợp nhất đến sự nhân nhanh in vitro cây Giảo cổ lam.

\subsection{Khảo sát ảnh hưởng của IBA đến sự tái sinh rễ in vitro}

Khả năng tái sinh rễ in vitro của chồi cây sau 20 ngày nuôi cấy được thể hiện trên Bảng 3. Kết quả cho thấy, ở môi trường không có chất kích thích sinh trưởng thì tất cả các mẫu đều tái sinh rễ, cây khỏe mạnh và có màu xanh đậm (Hình $1 \mathrm{~d}$ ), điều này cho thấy cây Giảo cổ lam là một đối tượng dễ tái sinh rễ in vitro. Môi trường bổ sung các nồng độ IBA khác nhau thì tất cả các mẫu cũng đều tái sinh rễ, cây khỏe mạnh và có màu xanh đậm (Hình $1 \mathrm{~d}$ ), tuy nhiên ở những nồng độ khác nhau thì quá trình tái sinh rễ có sự khác nhau. Khi nồng độ IBA tăng từ 0 lên $1 \mathrm{mg} / 1$ thì số rễ tăng lên (tương ứng 4.80, 7.30, 9.10, 12 rễ/cây), nhưng chiều dài rễ giảm xuống (tương ứng 2.67, 2.14, 1.86, $1.13 \mathrm{~cm}$ ). Điều này cho thấy, khi nồng độ IBA thấp thì kích thích tăng chiều dài rễ, nhưng khi tăng nồng độ IBA thì ức chế sự tăng trưởng theo chiều dài của rễ. IBA là chất kích thích sinh trưởng thuộc nhóm auxin có tác dụng kích thích tái sinh rễ và hiện nay đã sử dụng phổ biến trong các phòng thí nghiệm để nghiên cứu tái sinh rễ in vitro.

\begin{tabular}{|c|c|c|c|c|}
\hline IBA (mg/l) & Chiều cao cây $(\mathrm{cm})$ & Chiều dài rễ $(\mathrm{cm})$ & Số rễ/cây & Tỉ lệ tạo rễ (\%) \\
\hline 0.0 & $3.42^{\mathrm{b}}$ & $2.67^{\mathrm{a}}$ & $4.80^{\mathrm{d}}$ & 100 \\
\hline 0.1 & $4.29^{\mathrm{a}}$ & $2.14^{\mathrm{ab}}$ & $7.30^{\mathrm{c}}$ & 100 \\
\hline 0.5 & $3.67^{\mathrm{ab}}$ & $1.86^{\mathrm{b}}$ & $9.10^{\mathrm{b}}$ & 100 \\
\hline 1.0 & $2.63^{c}$ & $1.13^{\mathrm{c}}$ & $12.00^{\mathrm{a}}$ & 100 \\
\hline
\end{tabular}

Ghi chú: *Những chữ khác nhau $(\mathrm{a}, \mathrm{b}, \mathrm{c}, \mathrm{d})$ trong cùng một cột biểu diễn sự khác nhau có ý nghĩa với $P \leq 0.05$ trong Duncan's test; $\mathrm{n}=12$.

Kết quả của thí nghiệm này cũng tương đồng với kết quả nghiên cứu của Bùi và ctg. (2015) khi nghiên cứu nhân giống in vitro cây Giảo cổ lam đã sử dụng IBA, kết quả cho thấy, chồi tạo rễ in vitro $100 \%$ và cây đạt tiêu chuẩn. Pham và Tran (2017) nghiên cứu nhân giống cây Giảo cổ lam và cho thấy IBA là chất kích thích sinh trưởng phù hợp cho quá trình tái rễ in vitro của chồi cây. Zhang và ctg. (1988) nghiên cứu nhân giống vô tính cây Giảo cổ lam và cũng đã sử dụng IBA cho quá trình tái sinh rễ in vitro của chồi cây. Như vậy, nồng độ $\mathrm{IBA}$ từ 0 đến $1 \mathrm{mg} / \mathrm{l}$ đều thích hợp đến sự tái sinh rễ in vitro của cây Giảo cổ lam. 


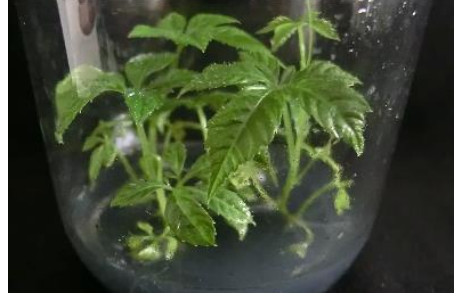

(a)

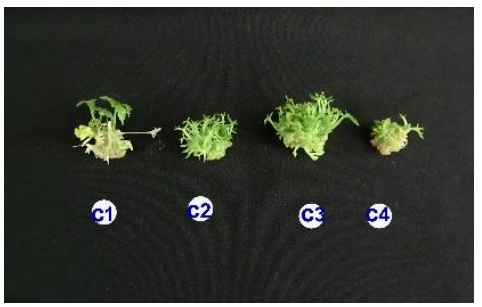

(c)

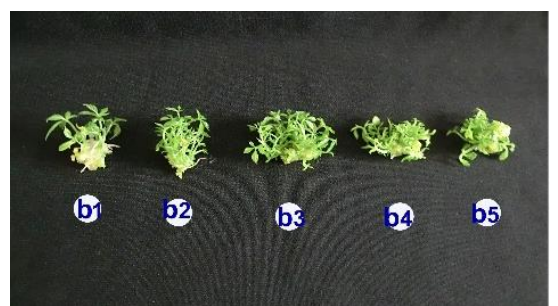

(b)

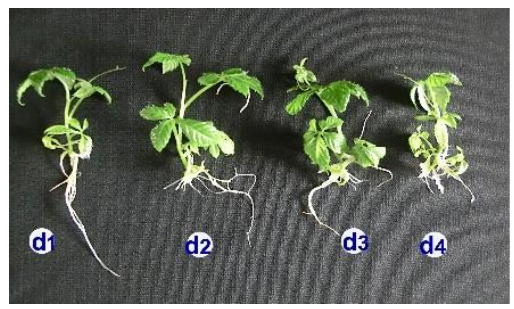

(d)

Hình 1. Nghiên cứu nhân giống in vitro và sự sinh trưởng phát triển cây Giảo cổ lam (Gynostemma pubescens) trong nhà kính.

Ghi chú: a) Cây Giảo cổ lam in vitro; $\mathrm{b}_{1}, \mathrm{~b}_{2}, \mathrm{~b}_{3}, \mathrm{~b}_{4}, \mathrm{~b}_{5}$ ) Tái sinh chồi in vitro trên môi trường bổ sung 0 , $0.5,1,1.5,2 \mathrm{mg} / 1 \mathrm{BA} ; \mathrm{c}_{1}, \mathrm{c}_{2}, \mathrm{c}_{3}, \mathrm{c}_{4}$ ) Tái sinh chồi in vitro trên môi trường bổ sung $0,0.1,0.5,1 \mathrm{mg} / \mathrm{TDZ}$; và $\mathrm{d}_{1}, \mathrm{~d}_{2}, \mathrm{~d}_{3}, \mathrm{~d}_{4}$ ) Tái sinh rễ in vitro trên môi trường bổ sung $0,0.1,0.5,1 \mathrm{mg} / 1 \mathrm{IBA}$.

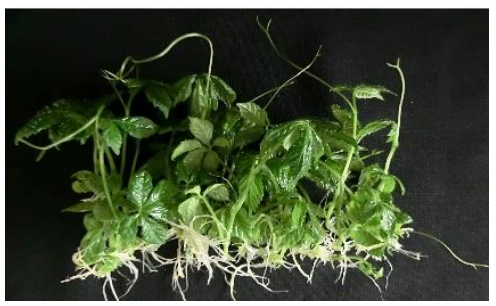

(a)

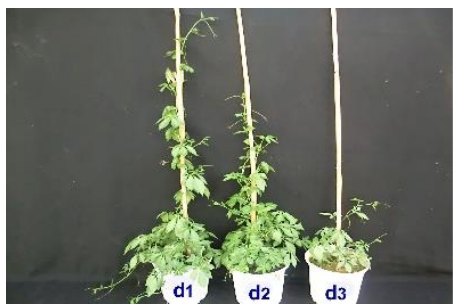

(c)

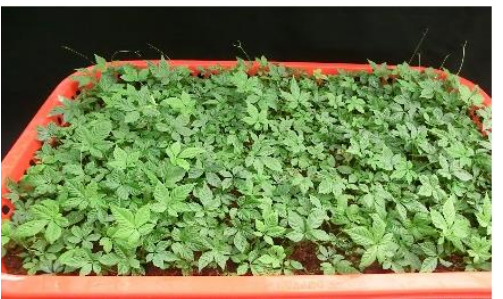

(b)

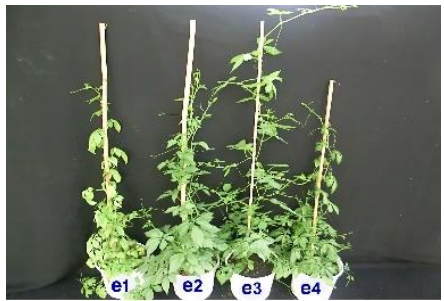

(e)

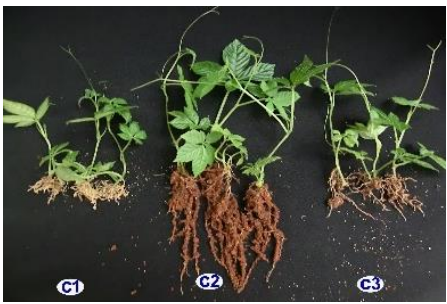

(c)

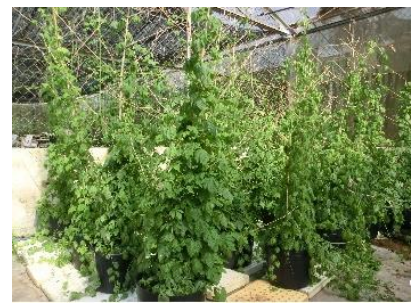

(f)

Hình 2. Nghiên cứu nhân giống in vitro và sự sinh trưởng phát triển cây Giảo cổ lam (Gynostemma pubescens) trong nhà kính.

Ghi chú: a) Cây Giảo cổ lam in vitro; b) Cây Giảo cổ lam cấy mô đã thích nghi ở điều kiện vườn ươm; $\mathrm{c}_{1}$, $\mathrm{c}_{2}, \mathrm{c}_{3}$ ) Cây Giảo cổ lam cấy mô trồng trên giá thể cát, vụn xơ dừa, $1 / 2$ cát $+1 / 2$ vụn xơ dừa; $\mathrm{d}_{1}, \mathrm{~d}_{2}, \mathrm{~d}_{3}$ ) Cây Giảo cổ lam cấy mô trồng trên giá thể đất mùn, vụn xơ dừa, đất bazan; $\mathrm{e}_{1}, \mathrm{e}_{2}, \mathrm{e}_{3}, \mathrm{e}_{4}$ ) Cây Giảo cổ lam cấy mô được tưới phân Phân hữu cơ sinh học bón lá Vinh Thanh Humic Acid, Nutri-Gold, Nitrophoska, Growmore; và f) Sự sinh trưởng phát triển cây Giảo cổ lam cấy mô sau 180 ngày trồng trong nhà kính. 


\subsection{Khảo sát ảnh hưởng của giá thể đến tỉ lệ sống của cây Giảo cổ lam cấy mô chuyển ra ngoài vườn ươm}

Khả năng thích nghi và sinh trưởng của cây giảo cổ lam cấy mô chuyển ra ngoài vườn ươm sau 45 ngày nuôi trồng và chăm sóc trên giá thể cát, vụn xơ dừa và giá thể $1 / 2$ vụn xơ dừa kết hợp với $1 / 2$ cát được thể hiện trên Bảng 4 . Chuyển cây cấy mô ra điều kiện ngoài vườn ươm là một khâu quan trọng quyết định thành công trong nuôi cấy mô thực vật. Cây cấy mô nuôi cấy trên môi trường thạch nên khi chuyển ra ngoài vườn ươm phải thích nghi trên những giá thể mới, độ ẩm thấp và có sự dao động trong ngày. Vì vậy, trong thời gian đầu cần phải phun sương giữ ẩm thích hợp cho cây. Kết quả cho thấy, tỉ lệ sống của cây con trồng ở các loại giá thể trên đều đạt $100 \%$, điều này cho thấy, cây Giảo cổ lam cấy mô có sức sống mạnh khi chuyển từ điều kiện in vitro ra điều kiện $e x$ vitro. Cây con trồng ở các loại giá trên cũng đều sinh trưởng phát triển tốt, tuy nhiên ở những giá thể khác nhau thì sự sinh trưởng của cây có sự khác nhau (Hình 2c). Cây trồng trên giá thể vụn xơ dừa sinh trưởng phát tốt nhất, với chiều cao cây $9.73 \mathrm{~cm}$, chiều dài rễ $6.45 \mathrm{~cm}$. Điều này có thể giải thích, giá thể vụn xơ dừa có độ thông thoáng và giữ ẩm thích hợp cho sự sinh trưởng phát triển của cây con trong giai đoạn đầu ở điều kiện ngoài vườn ươm.

Giá thể vụn xơ dừa là một trong những giá thể được sử dụng phổ biến để trồng cây con ở giai đoạn vườn ươm. Phan và Nguyễn (2014) đã nghiên cứu nhân giống và nuôi trồng cây dược liệu đảng sâm khi chuyển cây cấy mô ra ngoài vườn đã sử dụng giá thể vụn xơ dừa, kết quả cho thấy, tỉ lệ sống của cây đạt $100 \%$, chiều cao cây $6.12 \mathrm{~cm}$ và chiều dài rễ $4.60 \mathrm{~cm}$ sau 20 ngày nuôi trồng. Một nghiên cứu khác của Phan và ctg. (2018) cũng nghiên cứu cây dược liệu lan gấm loài Anoectochilus formosanus và đã sử dụng giá thể vụn xơ dừa để chuyển cây cấy mô ra ngoài vườn ươm, kết quả ghi nhận, tỉ lệ sống của cây con đạt $100 \%$ và cây sinh trưởng tốt. Kết quả của thí nghiệm này tốt hơn kết quả của Pham và Tran (2017) khi nghiên cứu chuyển cây Giảo cổ lam cấy mô ra ngoài vườn ươm thì tỉ lệ sống chỉ đạt $85 \%$. Như vậy, vụn xơ dừa là giá thể thích hợp nhất để chuyển cây Giảo cổ lam cấy mô ra ngoài vườn ươm.

Bảng 4. Ảnh hưởng của giá thể đến tỉ lệ sống của cây Giảo cổ lam cấy mô ch
\begin{tabular}{llll} 
ra ngoài vườn ươm sau & $\mathbf{4 5}$ ngày chăm sóc \\
\hline Giá thể & Chiều cao cây $(\mathrm{cm})$ & Chiều dài rễ $(\mathrm{cm})$ & Tỉ lệ sống $(\%)$ \\
\hline Cát & $6.41^{\mathrm{c}^{*}}$ & $2.39^{\mathrm{c}}$ & 100 \\
Vụn xơ dừa & $9.73^{\mathrm{a}}$ & $6.45^{\mathrm{a}}$ & 100 \\
$1 / 2$ vụn xơ dừa $+1 / 2$ cát & $7.52^{\mathrm{b}}$ & $3.56^{\mathrm{b}}$ & 100 \\
\hline
\end{tabular}

Ghi chú: *Những chữ khác nhau $(\mathrm{a}, \mathrm{b}, \mathrm{c})$ trong cùng một cột biểu diễn sự khác nhau có ý nghĩa với $P \leq 0.05$ trong Duncan's test; $\mathrm{n}=12$. 


\subsection{Khảo sát ảnh hưởng của giá thể đến sự sinh trưởng phát triển của cây Giảo cổ lam cấy mô trong nhà kính}

Những cây Giảo cổ lam cấy mô đã thích nghi ở điều kiện ngoài vườn ươm được trồng trên giá thể đất mùn, vụn xơ dừa và đất bazan. Tất cả các nghiệm thức đều tưới $100 \mathrm{ml}$ phân Nutri-Gold với nồng độ $2 \mathrm{~g} / \mathrm{l}$ vào chậu giá thể theo định kỳ mỗi tuần một lần. Khả năng sinh trưởng phát triển của cây sau 90 ngày nuôi trồng và chăm sóc được thể hiện trên Bảng 5 . Kết quả cho thấy, tỉ lệ sống của cây trồng ở các loại giá thể trên đều đạt $100 \%$, cây sinh trưởng phát triển tốt, lá cây có màu xanh đậm (Hình $2 \mathrm{~d}$ ), tuy nhiên ở những giá thể khác nhau thì cây có sự sinh trưởng phát triển khác nhau. Cây trồng trên giá thể đất mùn sinh trưởng phát triển tốt nhất, với chiều cao cây $82.08 \mathrm{~cm}$, chiều dài rễ $36.57 \mathrm{~cm}$, khối lượng tươi $57.32 \mathrm{~g} / \mathrm{cây}$. Cây trồng trên giá thể vụn xơ dừa không tốt bằng cây trồng ở giá thể đất mùn nhưng tốt hơn cây trồng trên giá thể đất bazan, với chiều cao cây $71.54 \mathrm{~cm}$, chiều dài rễ $34.58 \mathrm{~cm}$, khối lượng tươi $53.52 \mathrm{~g} /$ cây. Điều này có thể giải thích, đất mùn được hình thành trong đất do quá trình tích lũy và phân giải không hoàn toàn trong điều kiện yếm khí xác thực vật, giàu chất khoáng và tươi xốp phù hợp cho cây Giảo cổ lam cấy mô sinh trưởng phát triển.

Đất mùn là giá thể được sử dụng phổ biến trong trồng trọt. Hầu hết các vườn ươm giống cây con tại Đà Lạt, Lâm Đồng đều sử dụng đất mùn. Quan và Liang (2017) nghiên cứu bốn loại đất, bao gồm đất mùn, đất cát, đất vườn và đất nâu vàng để trồng loài Lycoris aurea. Kết quả phân tích cho thấy có sự khác biệt đáng kể về hàm lượng của các nguyên tố khoáng chất và hoạt động của các enzym trong các loại đất, trong đó, hàm lượng chất hữu cơ, nitơ thủy phân kiềm, $\mathrm{Ca}, \mathrm{Mg}$ cũng như hoạt động của các enzym trong đất mùn là cao nhất và đất mùn có thể được sử dụng làm giá thể thích hợp cho trồng trọt nhân tạo loài Lycoris aurea. Như vậy, giá thể đất mùn là thích hợp nhất đến sự sinh trưởng phát triển cây Giảo cổ lam cấy mô trong nhà kính.

Bảng 5. Ảnh hưởng của giá thể đến sự sinh trưởng phát triển của cây Giảo cổ lam cấy mô trong nhà kính sau 90 ngày nuôi trồng

\begin{tabular}{lllll}
\hline Giá thể & Chiều cao cây $(\mathrm{cm})$ & Chiều dài rễ $(\mathrm{cm})$ & Khối lượng tươiicây $(\mathrm{g})$ & Tỉ lệ sống $(\%)$ \\
\hline Đất mùn & $82.08^{\mathrm{a}}$ & $36.57^{\mathrm{a}}$ & $57.32^{\mathrm{a}}$ & 100 \\
Vụn xơ dừa & $71.54^{\mathrm{b}}$ & $34.58^{\mathrm{b}}$ & $53.52^{\mathrm{b}}$ & 100 \\
Đất bazan & $48.56^{\mathrm{c}}$ & $35.52^{\mathrm{ab}}$ & $30.56^{\mathrm{c}}$ & 100 \\
\hline
\end{tabular}

Chú thích: *Những chữ khác nhau $(\mathrm{a}, \mathrm{b}, \mathrm{c})$ trong cùng một cột biểu diễn sự khác nhau có ý nghĩa với $P \leq 0.05$ trong Duncan's test; $\mathrm{n}=12$.

\subsection{Khảo sát ảnh hưởng của phân bón đến sự sinh trưởng phát triển cây Giảo cổ lam cấy mô trong nhà kính}

Những cây Giảo cổ lam cấy mô đã thích nghi ở điều kiện ngoài vườn ươm được trồng trên giá thể đất mùn. Mỗi nghiệm thức được sử dụng các loại phân bón khác nhau, với nồng độ $2 \mathrm{~g} / \mathrm{l}$ và tưới $100 \mathrm{ml}$ vào chậu giá thể theo định kỳ mối tuần một lần. Khả 
năng sinh trưởng phát triển của cây sau 90 ngày nuôi trồng và chăm sóc được thể hiện trên Bảng 6. Kết quả cho thấy, tất cả các cây tưới bốn loại phân đều sống sót $100 \%$ và sinh trưởng phát triển tốt, nhưng ở mỗi nghiệm thức tưới các loại phân khác nhau thì cây sinh trưởng phát triển khác nhau. Cây tưới phân Nitrophoska sinh trưởng phát triển tốt nhất, với chiều cao $94.22 \mathrm{~cm}$, chiều dài rễ $37.71 \mathrm{~cm}$, khối lượng tươi $59.38 \mathrm{~g} /$ cây, cây có sức sinh trưởng mạnh và có mày xanh đậm (Hình $2 \mathrm{e}$ ). Cây tưới phân Growmore sinh trưởng phát triển kém nhất, với chiều cao cây $75.54 \mathrm{~cm}$, chiều dài rễ $28.58 \mathrm{~cm}$, khối lượng tươi $48.46 \mathrm{~g} /$ cây và lá cây có màu xanh đậm (Hình $2 \mathrm{~d}$ ). Cây tưới phân hữu cơ sinh học bón lá Vinh Thanh Humic Acid sinh trưởng phát triển tốt hơn cây tưới Growmore nhưng lá cây có màu xanh nhạt (Hình $2 \mathrm{~d}$ ), với chiều cao cây $79.34 \mathrm{~cm}$, chiều dài rễ $30.48 \mathrm{~cm}$, khối lượng tươi $52.58 \mathrm{~g} / \mathrm{cây}$. Cây tưới phân Nutri-Gold không tốt bằng cây tưới phân Nitrophoska nhưng tốt hơn cây tưới phân hữu cơ sinh học bón lá Vinh Thanh Humic Acid và phân Growmore, với chiều cao cây $83.56 \mathrm{~cm}$, chiều dài rễ $35.54 \mathrm{~cm}$, khối lượng tươi $54.98 \mathrm{~g} /$ cây và lá cây có màu xanh nhạt (Hình $2 \mathrm{~d}$ ). Điều này cho thấy, thành phần và hàm lượng của các chất khoáng đa vi lượng có trong phân Nitrophoska phù hợp cho sự sinh trưởng phát triển của cây Giảo cổ lam. Thực vật nói chung và cây Giảo cổ lam nói riêng đều cần những chất khoáng đa vi lượng thiết yếu cho cây sinh trưởng và phát triển, tuy nhiên những loại cây khác nhau thì nó cần những chất khoáng đa vi lượng và ở những nồng độ khác nhau.

\section{Bảng 6. Ảnh hưởng của phân bón đến sự sinh trưởng phát triển cây Giảo cổ lam cấy mô trong nhà kính sau 90 ngày nuôi trồng}

\begin{tabular}{lllll}
\hline Giá thể & $\begin{array}{l}\text { Chiều cao cây } \\
(\mathrm{cm})\end{array}$ & $\begin{array}{l}\text { Chiều dài rễ̂́ } \\
(\mathrm{cm})\end{array}$ & $\begin{array}{l}\text { Khối lượng } \\
\text { tươi/cây }(\mathrm{g})\end{array}$ & $\begin{array}{l}\text { Tỉ lệ sống } \\
(\%)\end{array}$ \\
\hline $\begin{array}{l}\text { Phân hữu cơ sinh học bón lá } \\
\text { Vinh Thanh Humic Acid }\end{array}$ & $79.34^{\mathrm{c}}$ & $30.48^{\mathrm{c}}$ & $52.58^{\mathrm{c}}$ & 100 \\
Nutri-Gold & $83.56^{\mathrm{b}}$ & $35.54^{\mathrm{b}}$ & $54.98^{\mathrm{b}}$ & 100 \\
Nitrophoska & $94.22^{\mathrm{a}}$ & $37.71^{\mathrm{a}}$ & $59.38^{\mathrm{a}}$ & 100 \\
Growmore & $75.54^{\mathrm{d}}$ & $28.58^{\mathrm{d}}$ & $48.46^{\mathrm{d}}$ & 100 \\
\hline
\end{tabular}

Chú thích: *Những chữ khác nhau $(\mathrm{a}, \mathrm{b}, \mathrm{c}, \mathrm{d})$ trong cùng một cột biểu diễn sự khác nhau có ý nghĩa với $P \leq 0.05$ trong Duncan's test; $\mathrm{n}=12$.

Kết quả của nghiên cứu này cũng phù hợp với kết quả của Phan, Huỳnh và Nguyễn (2017) khi nghiên cứu nhân giống và nuôi trồng cây dược liệu sâm bố chính đã Tưới $100 \mathrm{ml}$ phân Nitrophoska với nồng độ $2 \mathrm{~g} / \mathrm{l}$ theo định kỳ mỗi tuần một lần vào chậu giá thể, kết quả thu được, cây sinh trưởng phát triển tốt, chiều cao cây đạt $60.82 \mathrm{~cm}$ và tất cả các cây đều ra hoa, sau 80 ngày nuôi trồng và chăm sóc. Kết quả của nghiên cứu này cũng phù hợp với kết quả của Phan, Nguyễn, Phùng, và Vũ (2016) khi nghiên cứu nhân giống và nuôi trồng cây lan gấm Anoectochilus lylei đã sử dụng phân Nitrophoska, Growmore và phân JIA6, kết qua cho thấy, cây phun phân JIA6 sinh trưởng phát triển tốt nhất với chiều cao cây $13.55 \mathrm{~cm}$, chiều dài rễ $8.15 \mathrm{~cm}$ và khối lượng tươi $2.42 \mathrm{~g} /$ cây, 
sau bốn tháng nuôi trồng. Như vậy, tưới phân Nitrophoska là thích hợp nhất đến sự sinh trưởng phát triển cây Giảo cổ lam cấy mô trong nhà kính.

\section{KẾT LUẬN}

Từ các kết quả thu được, chúng tôi rút ra kết luận là đã nhân giống in vitro thành công và cây Giảo cổ lam sinh trưởng, phát triển tốt trong điều kiện nhà kính tại Đà Lạt, Lâm Đồng. Môi trường MS bổ sung $1 \mathrm{mg} / \mathrm{l} \mathrm{BA}, 30 \mathrm{~g} / \mathrm{l}$ sucrose, $8 \mathrm{~g} / \mathrm{l}$ agar, $\mathrm{pH} 5.8$ là thích hợp nhất đến sự nhân nhanh in vitro cây Giảo cổ lam; Môi trường MS bổ sung $0.5 \mathrm{mg} / 1$ TDZ, 30g/l sucrose, $8 \mathrm{~g} / \mathrm{l}$ agar, pH 5.8 là thích hợp nhất đến sự nhân nhanh in vitro cây Giảo cổ lam; Nồng độ IBA từ 0 đến $1 \mathrm{mg} / \mathrm{l}$ đều thích hợp đến sự tái sinh rễ in vitro của cây Giảo cổ lam; Vụn xơ dừa là giá thể thích hợp nhất để chuyển cây Giảo cổ lam cấy mô ra ngoài vườn ươm; Giá thể đất mùn là thích hợp nhất đến sự sinh trưởng phát triển cây Giảo cổ lam cấy mô trong nhà kính; Tưới $100 \mathrm{ml}$ phân Nitrophoska theo định kỳ mỗi tuần một lần là thích hợp nhất đến sự sinh trưởng phát triển cây Giảo cổ lam cấy mô trong nhà kính.

\section{LỜI CẢM ƠN}

Chúng tôi chân thành cảm ơn Viện Nghiên cứu Khoa học Tây Nguyên, Viện Hàn lâm Khoa học và Công nghệ Việt Nam đã cấp kinh phí để chúng tôi thực hiện và hoàn thành nghiên cứu này.

\section{TÀI LIỆU THAM KHẢO}

Bùi, Đ. L., Nguyễn, T. T., Nguyễn, V. D., Nguyễn, V. B., Lã, V. H., \& Ngô, X. B. (2015). Nghiên cứu khả năng nhân giống cây Giảo cổ lam (Gynostemma pentaphyllum Thunb) bằng phương pháp in vitro. Tạp chí Nông nghiệp và Phát triển Nông thôn, (15), 249-256.

Cheng, T. C, Lu, J. F, Wang, J. S., Lin, L. J., Kuo, H. I., \& Chen, B. H. (2011). Antiproliferation effect and apoptosis mechanism of prostate cancer cell PC-3 by flavonoids and saponins prepared from Gynostemma pentaphyllum. Journal of Agricultural and Food Chemistry, 59(20), 11319-11329.

Duncan, D. B. (1955). Multiple range and F tests. Biometrics, 11, 1-42.

Đoàn, T. Đ. (2014). Qui trình nhân giống cây đảng sâm bằng phuơng pháp nuôi cấy mô. Kon Tum, Việt Nam: Sở Khoa học và Công nghệ Kon Tum.

Đỗ, T. L. (1999). Nhũng cây thuốc và vị thuốc Việt Nam. Hà Nội, Việt Nam: NXB. Y học.

Huo, H., Wang, T., Yu, S., \& Xiao, P. (1998). Protective effect of saponins of Gynostemma pubescens on neuronal injury in cultured cortical neurons of mice. China Pharmaceutical Bulletin, 14(2), 120-122. 
Jala, A., \& Patchpoonporn, W. (2012). Effect of BA, NAA and 2.4-D on micropropagation of Jiaogulan (Gynostemma pentaphyllum Makino). International Transaction Journal of Engineering, Management, \& Applied Sciences \& Technologies, 3(4), 362-369.

Li, Y., Lin, W., Huang, J., Xie, Y., \& Ma, W. (2016). Anti-cancer effects of Gynostemma pentaphyllum (Thunb.) Makino. Chinese Medicine, 11, 1-16.

Murashige, T., \& Skoog, F. (1962). A revised medium for rapid growth and bioassays with tobacco tissue. Journal of Plant Physiology, 15, 473-497.

Phan, X. H., Hoàng, V. C., Đinh, V. K., Nguyễn, T. T. H., \& Nguyễn, L. T. (2015). Vi nhân giống cây hoa lan Miltonia sp. Tạp chí Công nghệ Sinh học, 13(2A), 459467.

Phan, X. H., Huỳnh, T. N., \& Nguyễn, T. P. H. (2017). Nghiên cứu nhân giống in vitro cây sâm bố chính (Hibicus sagittifolius Kurz) thông qua nuôi cấy chồi ngủ đốt thân. Tạp chí Khoa học Nông nghiệp Việt Nam, 15(5), 664-672.

Phan, X. H., Nguyễn, T. T. H., Phùng, Q. V., \& Vũ, T. H. (2016). Nghiên cứu nhân giống và nuôi trồng cây lan gấm (Anoectochilus lylei Rolfe ex Downies). Tạp chí Khoa học Đại học Tây Nguyên, (20), 68-74.

Phan, X. H., Trần, T. H. A., Nguyễn, T. P. H., Nguyễn, T. T. H., Đinh, V. K., \& Hoàng, V. C. (2018). Nhân giống in vitro và ảnh hưởng của phân bón lá đến sự sinh trưởng cây lan gấm tại Lâm Đồng. Tạp chi Dược liệu, 23(1), 52-59.

Phan, X. H., \& Nguyễn, L. T. (2014). Nghiên cứu nhân giống in vitro cây đảng sâm (Codonopsis javanica Blume) thông qua nuôi cấy chồi ngủ. Tạp chí Công nghệ Sinh hoc, 12(4), 659-666.

Pham, C. K., \& Tran, V. M. (2017). Preservation and development of Giao co lam (Gynostemma pentaphyllum) in the hot tropics of Vietnam. Paper presented at The Sixth International Conference on Advances in Applied Science and Environmental Technology, USA.

Quan, M. H., \& Liang, J. (2017). The influences of four types of soil on the growth, physiological and biochemical characteristics of Lycoris aurea (L' Her.) Herb. Scientific Reports, 7, 1-9.

Slupski, W., Tubek, B., \& Matkowski, A. (2011). Micropropagation of Codonopsis pilosula (Franch.) Nannf. by axillary shoot multiplication. Acta Biologica Cracoviensia, 53(2), 87-93.

Utama-ang, N., Chompreeda, P., Haruthaithanasan, V., Lerdvuthisopon, N., Suwonsichon, T., Wood, K., \& Watkins, B. A. (2006). Identification of major saponins from Jiaogulan extract (Gynostemma pentaphyllum). Kasetsart Journal, 40, 59-66.

Võ, V. C. (1997). Tù điển Cây thuốc Việt Nam. Hà Nội, Việt Nam: NXB. Y học. 
Xie, Z., Liu, W., Huang, H., Slavin, M., Zhao, Y., Whent, M., Blackford, J., Lutterodt, H., Zhou, H., Chen, P., Wang, T. T., Wang, S., \& Yu, L. L. (2010). Chemical composition of five commercial Gynostemma pentaphyllum samples and their radical scavenging, antiproliferative, and anti-inflammatory properties. Journal of Agricultural and Food Chemistry, 58(21), 11243-11249.

Yin, F., \& Hu, L. H. (2016). Studies on chemical constituents of Jiaogulan (Gynostemma pentaphyllum). Herbs: Challenges in Chemistry and Biology, 13, 170-184.

Zhang, Z. H., Liu, H., Zhao, L. H., \& Han, X. Z. (1988). Clonal propagation of Gynostemma pentaphyllum (Thumb.) Makino in test tubes. Zhongguo Zhong Yao Za Zhi, 14(6), 335-341. 